Bogdan LANDOWSKI, Łukasz MUŚLEWSKI, Klaudiusz MIGAWA, Daniel PERCZYŃSKI

University of Science and Technology (Uniwersytet Technologiczno-Przyrodniczy)

\title{
ANALYSIS OF FAILURES OF SELECTED TECHNICAL OBJECTS
}

\author{
Analiza uszkodzeń wybranych obiektów technicznych
}

\begin{abstract}
The article deals with selected issues concerning tests results of failures of selected objects used in the analyzed real technical system. The main operation goal of the analyzed system is to provide passengers with safe transport services within a given quantitative range and over a given territory. The analyzed technical objects were transport means. Transport services were provided along scheduled routes. Selected features and characteristics of vehicle failures have been discussed. Vehicles used in the investigated technical object were disassembled for the needs of the research. Tests were performed with the use of the passive experiment method under real service conditions.
\end{abstract}

Keywords: urban transport, reliability, damage, transport

Streszczenie: W pracy przedstawiono wybrane wyniki badań dotyczące uszkodzeń obiektów technicznych użtkowanych w analizowanym rzeczywistym systemie eksploatacji. Gtównym celem działania, rozpatrywanego w pracy, systemu eksploatacji jest bezpieczne przewożenie pasażerów w wyznaczonym zakresie ilościowym i terytorialnym. Analizowanymi obiektami technicznymi sa środki transportu. Zadania przewozowe polegały na realizacji przewozów pasażerskich na wyznaczonych trasach komunikacyjnych. Ponadto poddano analizie wybrane cechy i charakterystyki uszkodzeń pojazdów. Dla potrzeb pracy dokonano dekompozycji pojazdów eksploatowanych $w$ obiekcie badań. Badania przeprowadzono metoda eksperymentu biernego w naturalnych warunkach eksploatacji.

Słowa kluczowe: komunikacja miejska, niezawodność, uszkodzenie, transport 


\section{Introduction}

Transport plays a key role in the economic life of a society. Road transport is an important branch of economy as it makes it possible for passengers and cargo to be carried on the land with the use of transport means, usually over short and medium distances. City passenger transport needs to be distinguished not only due to its spatial character but also specificity of its operation in terms of economy $[15,16]$.

During service, technical states of transport means undergo changes. A vehicle consists of many dependent on each other mechanisms. Each mechanism is exposed to a variety of external factors of random character which affect the processes responsible for the wear of its components which in consequence leads to occurrence of failures $[1,2,4,9,14]$.

In order to determine indicators of technical object reliability and make analyses of reliability for transport systems, it is necessary to obtain and process information on the operation and maintenance of the transport means. Thus, investigations need to be performed in a real technical system of transport means operation $[4,7,12]$.

The analysis of the results of tests, including the tests of models of changes in object states, enables to take rational actions that increase the level of reliability and safety of technical objects. Both analytical and simulation methods are used to analyse processes of changes in object states, including those related to the occurrence of damages at random moments of time. Random stochastic processes, including a homogenous Markov and semiMarkov processes, are commonly used for modeling of operational states $[3,5,6,10,12,14]$.

An analysis of results of tests performed under real service conditions can provide people involved in technical systems management with the basis for making right decisions, thus improving operational efficiency of these systems $[4,9,11,13,16]$.

The research object of this study is a system of city bus transport operating in a given urban agglomeration.

Smooth operation of the system determines operational efficiency of the transport means and their capability to provide the transport services [9].

The primary goal of the analyzed system operation is to provide passengers with transport services over an urban and suburban area of a given city. Suburban areas are qualified to be served by city transport on the basis of the demand of passenger for transport services in these areas. Particular tasks must be performed timely, and safely. The territorial and quantitative range of the transport tasks to be performed is established by managers of the analyzed transport system [16].

\section{The research method}

The main goal of the research was to make a quantitative analysis of failures of buses used in the analyzed city bus transport system. 
In the analyzed system, there are vehicles of different makes and types. The research program involved buses of two types. Each group consisted of 15 buses all of which provided services on a daily basis for a period of two years. The experimental tests were performed by the passive experiment method. Observation of the operation and maintenance process and recording data on failures was carried out under service conditions. In order to provide assessment and analysis of frequency of occurrence of the main subsystems and components failures a vehicle was decomposed. At the first level of decomposition there were 11 basic functional subsystems of the technical object. Terminology used is consistent with the one used in the investigated city bus transport system [8].

The following systems were chosen:

UK - steering system,

UZ - suspension system,

UE - electrical system,

UW - body,

UN - power transmission system,

UJ - wheels and steering system,

UO - power supply system,

UC - cooling system,

UP - pneumatic system,

US - drive system (engine),

UH - braking system.

Each of the analyzed vehicles was marked with an individual code. Codes of all the investigated buses make up $\mathrm{K}$ set. An i-th vehicle is to be understood as a vehicle marked with $i$ code, $i \in K$.

The length of the distance covered (in kilometers) in a given period of time was accepted to be a measure of transport tasks accomplishment.

Such indexes as: the number of failures of a particular vehicle $\mathrm{Lu}$, its components and subsystems that occurred in the analyzed period of time and relative index of failure frequency $\mathrm{W}_{\mathrm{i}}$ were used for quantitative analysis of the vehicle failures [1,2,4,7-9]. Relative failure index $\mathrm{W}_{\mathrm{i}}$ of a vehicle marked with code $\mathrm{i}$ is determined from dependence:

$$
\mathrm{W}_{\mathrm{i}}=\frac{\mathrm{Lu}_{\mathrm{i}} \cdot 1000}{1 \mathrm{k}_{\mathrm{i}}},[1 / \mathrm{km}]
$$

where:

$\mathrm{Lu}_{\mathrm{i}}-$ number of failures of the $\mathrm{i}$-th vehicle in the analyzed period,

$1 \mathrm{k}_{\mathrm{i}}$ - transport task accomplishment measure of the i-th vehicle [km],

i $\quad-$ vehicle code, $\mathrm{i} \in \mathrm{K}$. 


\section{Selected tests results}

In table 1 there are values of selected failure indexes. The number of failures of selected systems of a vehicle are presented in table 2 .

Table 1

Values of the analyzed indexes determined for particular vehicles marked with code $i$ [8]

\begin{tabular}{|c|c|c|c|c|c|}
\hline \multicolumn{3}{|c|}{ Vehicles of type I } & \multicolumn{3}{|c|}{ Vehicles of type II } \\
\hline $\mathbf{i}$ & $\mathbf{L u} \mathbf{u}_{\mathrm{i}}$ & $\mathbf{W}_{\mathbf{i}}$ & $\mathbf{i}$ & $\mathbf{L u}_{\mathrm{i}}$ & $\mathbf{W}_{\mathbf{i}}$ \\
\hline $\mathrm{k} 23$ & 185 & 1,13 & n59 & 38 & 0,34 \\
\hline k33 & 232 & 1,62 & n60 & 93 & 0,47 \\
\hline k34 & 184 & 1,13 & n61 & 65 & 0,37 \\
\hline k37 & 206 & 1,01 & n62 & 71 & 0,35 \\
\hline k39 & 221 & 1,52 & n64 & 125 & 0,62 \\
\hline k44 & 168 & 1,24 & n65 & 93 & 0,53 \\
\hline $\mathrm{k} 45$ & 211 & 0,98 & n66 & 128 & 0,59 \\
\hline $\mathrm{k} 48$ & 262 & 0,99 & $\mathrm{n} 67$ & 115 & 0,59 \\
\hline k49 & 173 & 0,9 & $\mathrm{n} 70$ & 91 & 0,42 \\
\hline $\mathrm{k} 27$ & 454 & 3,16 & $\mathrm{n} 71$ & 51 & 0,24 \\
\hline k29 & 430 & 2,9 & n63 & 184 & 1,8 \\
\hline k31 & 508 & 3,07 & n68 & 278 & 1,49 \\
\hline k35 & 95 & 0,95 & n69 & 321 & 1,78 \\
\hline $\mathrm{k} 38$ & 371 & 2,49 & $\mathrm{n} 72$ & 88 & 0,88 \\
\hline $\mathrm{k} 42$ & 316 & 2,86 & $\mathrm{n} 73$ & 107 & 0,85 \\
\hline Average & 268 & 1,73 & Average & 123 & 0,75 \\
\hline Standard deviation & 120,97 & 0,89 & Standard deviation & 80,10 & 0,52 \\
\hline Coefficient of variation & 0,45 & 0,51 & Coefficient of variation & 0,65 & 0,69 \\
\hline
\end{tabular}

Electric system failures account for almost 30\% of all recorded failures. Most of them were found and removed during the so called daily servicing by a standby service team between successive runs. As many as $50 \%$ of all repairs of electric systems are connected with exchange of the fuse whereas, $20 \%$ of repairs are connected with exchange and repair of the external lights. Damage to the doors accounted for $80 \%$ to $90 \%$ of all body repairs. Removal of failures usually involved adjustment of pneumatic elements (valves) that control of the door opening and closing.

It should be emphasized that a door failure is very important from the point of view of transport task accomplishment. Passenger door failure makes it impossible to continue 
performance of a transport task due to safety of passengers. Components that undergo the most frequent damage in a pneumatic system are pneumatic pipes and valves. Failures of these components account for nearly $50 \%$ of all the recorded failures of these systems. $80 \%$ of failures of the cooling system were caused by damage to rubber elements. Failure of the suspension system involved damage to its pneumatic rubber elements, that is an airbag and its main pneumatic valve. As for the steering system, it was the hydraulic power steering that most often underwent damage. As many as $90 \%$ of the repairs of wheels involved replacement or renewal of tires. The remaining failures of this system were connected with bearings of hubs and the swivel pin. The most frequently reported failures of the braking systems were those of its pneumatic elements as well as leaks of the brake ducts [8].

Table 2

\section{Number of failures reported in the analyzed vehicles systems [8]}

\begin{tabular}{|c|c|c|}
\hline \hline SYSTEM CODE & Type I vehicles & Type II vehicles \\
\hline UK & 61 & 7 \\
\hline UH & 198 & 167 \\
\hline UZ & 50 & 29 \\
\hline UE & 1375 & 780 \\
\hline UW & 690 & 500 \\
\hline UN & 63 & 16 \\
\hline UJ & 103 & 80 \\
\hline US & 268 & 47 \\
\hline UO & 212 & 12 \\
\hline UC & 434 & 109 \\
\hline UP & 562 & 91 \\
\hline Total & $\mathbf{4 0 1 6}$ & $\mathbf{1 8 4 8}$ \\
\hline
\end{tabular}

In order to evaluate the impact of failures on performance efficiency of the analyzed vehicles, they were divided into significant and insignificant transport task accomplishment. Significant failures are such that cause elimination of the vehicle from service and a backup vehicle needs to be used.

Insignificant failures can be repaired by standby services during a break between two runs or during daily servicing. The number of failures significant and insignificant for the ability to accomplish the transport tasks are shown in table 3. 
Table 3

The number of failures significant and insignificant for accomplishment of transport tasks [8]

\begin{tabular}{|c|c|c|c|c|c|}
\hline \multicolumn{3}{|c|}{ Vehicles of type I } & \multicolumn{3}{|c|}{ Vehicles of type II } \\
\hline $\mathbf{i}$ & Significant & Insignificant & $\mathbf{i}$ & Significant & Insignificant \\
\hline $\mathrm{k} 23$ & 54 & 131 & n59 & 12 & 26 \\
\hline k33 & 48 & 184 & n60 & 20 & 73 \\
\hline k34 & 32 & 152 & n61 & 12 & 53 \\
\hline k37 & 34 & 172 & n62 & 14 & 57 \\
\hline k39 & 52 & 169 & n64 & 25 & 100 \\
\hline $\mathrm{k} 44$ & 40 & 128 & n65 & 17 & 76 \\
\hline $\mathrm{k} 45$ & 37 & 174 & n66 & 17 & 111 \\
\hline $\mathrm{k} 48$ & 47 & 215 & n67 & 19 & 96 \\
\hline k49 & 23 & 150 & $\mathrm{n} 70$ & 20 & 71 \\
\hline k27 & 98 & 356 & $\mathrm{n} 71$ & 9 & 42 \\
\hline $\mathrm{k} 29$ & 70 & 360 & n63 & 18 & 166 \\
\hline $\mathrm{k} 31$ & 66 & 442 & n68 & 29 & 249 \\
\hline k35 & 10 & 85 & n69 & 24 & 297 \\
\hline k38 & 62 & 309 & $\mathrm{n} 72$ & 18 & 70 \\
\hline $\mathrm{k} 42$ & 77 & 239 & $\mathrm{n} 73$ & 17 & 90 \\
\hline Average & 50 & 217,73 & Average & 18 & 105,13 \\
\hline $\begin{array}{l}\text { Standard } \\
\text { deviation }\end{array}$ & 22,43 & 102,84 & $\begin{array}{l}\text { Standard } \\
\text { deviation }\end{array}$ & 5,26 & 76,14 \\
\hline $\begin{array}{c}\text { Coefficient of } \\
\text { variation }\end{array}$ & 0,45 & 0,47 & $\begin{array}{c}\text { Coefficient of } \\
\text { variation }\end{array}$ & 0,29 & 0,72 \\
\hline
\end{tabular}

\section{Conclusions}

Prognosis of a transport system behavior and evaluation of the influence of selected decision variants can be used to support the management staff in making decisions concerning operation and maintenance of transport means used in the analyzed technical system. An analysis of tests results of the vehicle failures can be very useful for this purpose.

As many as $70 \%$ of all the failures of the analyzed vehicles were removed by the standby service units or within daily servicing. Failures insignificant for transport task accomplishment were reported most often. They were usually inexpensive and did not take 
much time to be repaired. It seems that a big part of such failures is connected with the failure register method used in the transport system and the methods for analysis of work time of employees of the subsystem providing vehicles with operability [8]. For buses of type I, an increased number of failures of the pneumatic system was reported in winter months as compared to the remaining months. Thus, it seems to be advisable to modify the procedure connected with daily servicing of this type of vehicles and introduce processes for diagnosis of the pneumatic system technical state as a prevention procedure.

Additionally, a possibility of limiting the number of transport services to be performed by I type buses should be considered as well as, whenever possible, successive elimination of buses of this type from service.

\section{References}

1. Gałdzicki Z., Gołąbek A.: Niezawodność autobusów. Wydawnictwo Politechniki Wrocławskiej, Wrocław 1993.

2. Inżynieria niezawodności, Poradnik, pod red. J. Migdalskiego, ZETOM, Warszawa 1992.

3. Kostek R., Landowski B., Muślewski Ł.: Simulation of rolling bearing vibration in diagnostics. Journal of Vibroengineering, vol. 17, iss. 8, 2015.

4. Landowski B., Chabowski Ł.: Analiza wybranych charakterystyk uszkodzeń środków transportu. Studia i Materiały Polskiego Stowarzyszenia Zarządzania Wiedzą/Studies \& Proceedings Polish Association for Knowledge Management, Nr 46, 2011.

5. Landowski B., Muślewski Ł., Pająk M., Polishchuk O.: Method for initial assessment of unit costs of public city transport means operation. MATEC Web of Conferences 182, 01010, 17th International Conference Diagnostics of Machines and Vehicles, 2018, DOI: 10.1051/matecconf/201818201010.

6. Landowski B., Pająk M., Żółtowski B., Muślewski Ł.: Method of building a model of operational changes for the marine combustion engine describing the impact of the damages of this engine on the characteristics of its operation process. Polish Maritime Research, no 4 (96), vol. 24, 2017.

7. Landowski B., Perczyński D., Kolber P., Muślewski Ł.: An example of Markov model of technical objects maintenance process. Engineering Mechanics 2016, 22nd International Conference, Book of full texts: Institute of Thermomechanics Academy of Sciences of the Czech Republic, 2016.

8. Landowski B., Perczyński D.: Analiza uszkodzeń autobusów komunikacji miejskiej. $12^{\text {th }}$ International Conference on Developments in Machinery Design and Control, Nowogród 2008, CD.

9. Landowski B., Woropay M., Neubauer A.: Sterowanie niezawodnością w systemach transportu. Wydawnictwo ITE, Radom 2004. 
10. Landowski B.: Numerical simulation of the process of a technical object state changes. Journal of KONBiN, vol. 45, 2018, DOI 10.2478/jok-2018-0013.

11. Muślewski Ł., Bojar P., Woropay M.: Identification and assessment of transport systems operations quality. Archives of Transport, 23 (3), 2011.

12. Muślewski Ł., Knopik L., Landowski B., Polishchuk O.: Analysis of assessment criteria for selected systems of transport means operation. MATEC Web of Conferences 182, 02003, 17th International Conference Diagnostics of Machines and Vehicles, 2018, DOI: 10.1051/matecconf/201818202003.

13. Muślewski Ł., Landowski B., Mackiewicz N., Pająk M.: Research and analysis of work ergonomics of selected transport means operators. International Automotive Conference (KONMOT 2018), Materials Science and Engineering, 1757-8981, 2018, DOI:10.1088/1757-899X/421/3/032020.

14. Pająk M., Muślewski Ł., Landowski B.: Optimisation of changes of the operation quality of the transportation system in the fuzzy quality states space. International Automotive Conference (KONMOT 2018), Materials Science and Engineering; 1757-8981, 2018, DOI:10.1088/1757-899X/421/3/032023.

15. Transport, pod red. W. Rydzkowski, K. Wojewódzka-Król, PWN, Warszawa 1998.

16. Woropay M., Knopik L., Landowski B.: Modelowanie procesów eksploatacji w systemie transportowym. Wydawnictwo ITE, Bydgoszcz - Radom 2001. 


\section{ANALIZA USZKODZEŃ WYBRANYCH OBIEKTÓW TECHNICZNYCH}

\section{Wstęp}

Transport odgrywa kluczową rolę w efektywnie działającym życiu gospodarczym. Ważną gałąź transportu stanowi transport samochodowy (drogowy), w którym ładunki oraz pasażerowie przemieszczają się po drogach lądowych przy pomocy kołowych środków transportu. Odpowiada on głównie za przewóz ludzi i ładunków na krótkie oraz średnie odległości. Wyodrębnienie problematyki pasażerskiego transportu miejskiego wynika nie tylko z przestrzennego zasięgu jego działania, ale także z jego specyfiki eksploatacyjnoekonomicznej $[15,16]$.

Środki transportu zmieniają swój stan techniczny w toku użytkowania. Pojazd samochodowy złożony z wielu mechanizmów wzajemnie ze sobą powiązanych jest poddawany działaniu wielu czynników zewnętrznych o charakterze losowym, które wpływają na procesy zużycia jego elementów, co w konsekwencji prowadzi do wystąpienia uszkodzenia $[1,2,4,9,14]$.

Do wyznaczania wartości wskaźników niezawodności obiektów technicznych oraz analiz niezawodności w systemach transportowych, niezbędne jest pozyskanie i przetworzenie informacji eksploatacyjnej. W tym celu konieczna jest realizacja badań w rzeczywistym systemie eksploatacji środków transportu [4,7,12].

Analiza wyników badań, również badań modeli zmian stanów obiektów, umożliwia podjęcie racjonalnych działań prowadzących do zwiększenia poziomu niezawodności i bezpieczeństwa obiektów technicznych. Do analizy procesów zmian stanów obiektów, w tym związanych z występowaniem w losowych chwilach czasu uszkodzeń wykorzystuje się zarówno metody analityczne, jak i symulacyjne. Powszechnie do modelowania zmian stanów eksploatacyjnych stosowane są jednorodne procesy stochastyczne, w tym jednorodne procesy Markowa i semi-Markowa [3,5,6,10,12,14].

Analiza wyników badań eksploatacyjnych zrealizowanych w naturalnych warunkach eksploatacji może stanowić podstawę do podjęcia działań przez decydentów systemu eksploatacji zmierzających do zwiększenia efektywności działania tego systemu $[4,9,11$, $13,16]$.

Obiektem badań, na którym zilustrowano rozważania przedstawione w niniejszej pracy, jest system eksploatacji autobusów komunikacji miejskiej w wybranej aglomeracji miejskiej. Prawidłowość działania tego systemu decyduje o efektywności eksploatacji użytkowanych obiektów i możliwościach realizacji wytyczonych zadań [9]. 
Podstawowym celem działania badanego systemu eksploatacji jest przewóz pasażerów na obszarze miejskim, jak i podmiejskim. Podstawą zakwalifikowania określonych obszarów podmiejskich, do obsługi przez transport miejski, jest charakter ruchu pasażerskiego na tych obszarach, determinowany przez spełnianą funkcję w stosunku do miasta. Poszczególne zadania transportowe powinny być realizowane terminowo i bezpiecznie. Zakres terytorialny oraz ilościowy realizowanych zadań przewozowych ustalany jest przez decydentów analizowanego systemu [16].

\section{Sposób realizacji badań}

Głównym celem badań było przeprowadzenie ilościowej analizy uszkodzeń autobusów komunikacji miejskiej eksploatowanych w analizowanym przedsiębiorstwie komunikacyjnym.

W obiekcie badań użytkowane są pojazdy różnych marek i typów. Opracowany program badań zrealizowano dla autobusów dwóch typów. Każda grupa liczyła po 15 autobusów. Wszystkie badane pojazdy realizowały swoje zadania przewozowe codziennie przez okres dwóch lat. Badania przeprowadzono metodą eksperymentu biernego. Obserwacja procesu ich eksploatacji oraz rejestracja danych o uszkodzeniach została przeprowadzona w warunkach normalnego użytkowania pojazdów. W celu oceny i analizy częstości uszkodzeń głównych podsystemów i elementów pojazdu dokonano jego dekompozycji. Na pierwszym poziomie dekompozycji wyróżniono 11 głównych układów autobusów. Zastosowany sposób podziału obiektu technicznego na główne układy funkcjonalne, a także zastosowana terminologia są zgodne $\mathrm{z}$ terminologią stosowaną w badanym systemie eksploatacji autobusów komunikacji miejskiej [8].

Poddano analizie następujące układy:

UK - układ kierowniczy,

UZ - układ zawieszenia,

UE - układ instalacji elektrycznej,

UW - układ nadwozie,

UN - układ przeniesienia napędu,

UJ - układ jezdny,

UO - układ zasilania,

UC - układ chłodzenia,

UP - układ pneumatyczny,

US - układ napędowy (silnik),

UH - układ hamulcowy.

Każdy z badanych pojazdów oznaczono indywidualnym kodem. Kody wszystkich badanych autobusów tworzą zbiór K. Przez i-ty pojazd należy rozumieć pojazd oznaczony kodem $i, i \in \mathrm{K}$. 
Jako miarę realizacji zadań przewozowych przyjęto długość drogi (w kilometrach) przebytej przez pojazd w analizowanym przedziale czasu.

Do analiz uszkodzeń pojazdów o charakterze ilościowym stosuje się m.in. takie wskaźniki jak [1,2,4,7-9]: liczbę uszkodzeń Lu poszczególnych pojazdów, ich podsystemów oraz elementów w analizowanym przedziale czasu oraz względny wskaźnik częstości uszkodzeń $\mathrm{W}_{\mathrm{i}}$.

Względny wskaźnik częstości uszkodzeń $\mathrm{W}_{\mathrm{i}}$ pojazdu oznaczonego kodem i wyznaczany jest z zależności:

$$
\mathrm{W}_{\mathrm{i}}=\frac{\mathrm{Lu}_{\mathrm{i}} \cdot 1000}{\mathrm{lk}_{\mathrm{i}}},[1 / \mathrm{km}]
$$

gdzie:

$\mathrm{Lu}_{\mathrm{i}}$ - liczba uszkodzeń $\mathrm{i}$ - tego pojazdu w okresie badań,

$\mathrm{lk}_{\mathrm{i}} \quad$ - miara realizacji zadań przewozowych $\mathrm{i}-$ tego pojazdu $[\mathrm{km}]$,

i $\quad-$ kod pojazdu, $i \in K$.

\section{Wybrane wyniki badań}

W tabeli 1 zestawiono wartości wybranych spośród analizowanych wskaźników uszkodzeń. Liczbę uszkodzeń wyróżnionych układów pojazdów zestawiono w tabeli 2.

Uszkodzenia instalacji elektrycznej stanowią prawie 30\% wszystkich odnotowanych uszkodzeń. Większość tych nieprawidłowości została wykryta i usunięta w ramach tzw. obsługi codziennej oraz przez jednostki pogotowia technicznego w czasie postoju autobusów pomiędzy kolejnymi kursami. Niemal 50\% wszystkich napraw instalacji elektrycznej związana jest z wymianą bezpiecznika, 20\% natomiast z wymianą bądź naprawą elementów oświetlenia zewnętrznego. W badanych pojazdach uszkodzenia drzwi stanowiły od $80 \%$ do 90\% wszystkich uszkodzeń nadwozia. Usuwanie ich polegało najczęściej na regulacji elementów pneumatycznych (zaworów) sterujących otwieraniem i zamykaniem drzwi. Należy podkreślić, że uszkodzenia drzwi są istotne z punktu widzenia możliwości realizacji zadania przewozowego. Usterka drzwi pasażerskich uniemożliwia kontynuację zadania przewozowego ze względu na bezpieczeństwo pasażerów. W układzie pneumatycznym najczęściej uszkadzającymi się elementami były przewody pneumatyczne oraz zawory. Uszkodzenia tych elementów stanowią około 50\% wszystkich odnotowanych uszkodzeń tego układu. Niezdatność układu chłodzenia badanych pojazdów niemal w 80\% spowodowana jest uszkodzeniem elementów gumowych tego układu. Usterki układu zawieszenia dotyczyły zwłaszcza jego elementów pneumatycznych, a więc poduszki powietrznej oraz jej głównego zaworu pneumatycznego. W przypadku układu jezdnego, napędowego, przeniesienia napędu oraz kierowniczego badanych pojazdów nie odnotowano istotnych uszkodzeń 
o charakterze powtarzalnym. W układach kierowniczych najczęściej uszkadzał się hydrauliczny układ wspomagania kierownicy. W przypadku układu jezdnego 90\% czynności naprawczych związana była z naprawą i wymianą ogumienia. Pozostałe uszkodzenia zlokalizowane w tym układzie dotyczą łożysk piasty oraz sworznia zwrotnicy. W układach hamulcowych badanych pojazdów najczęściej uszkadzały się elementy części pneumatycznej tego układu. Częstą przyczyną niezdatności układu hamulcowego były też nieszczelności w złączach przewodów hamulcowych [8].

Tabela 1

Wartości analizowanych wskaźników wyznaczone dla poszczególnych pojazdów oznaczonych kodem i [8]

\begin{tabular}{|c|c|c|c|c|c||}
\hline \multicolumn{3}{|c|}{ Pojazdy typu I } & \multicolumn{3}{c|}{ Pojazdy typu II } \\
\hline $\mathbf{i}$ & $\mathbf{L u}_{\mathbf{i}}$ & $\mathbf{W}_{\mathbf{i}}$ & $\mathbf{i}$ & $\mathbf{L u}_{\mathbf{i}}$ & $\mathbf{W}_{\mathbf{i}}$ \\
\hline $\mathrm{k} 23$ & 185 & 1,13 & $\mathrm{n} 59$ & 38 & 0,34 \\
\hline $\mathrm{k} 33$ & 232 & 1,62 & $\mathrm{n} 60$ & 93 & 0,47 \\
\hline $\mathrm{k} 34$ & 184 & 1,13 & $\mathrm{n} 61$ & 65 & 0,37 \\
\hline $\mathrm{k} 37$ & 206 & 1,01 & $\mathrm{n} 62$ & 71 & 0,35 \\
\hline $\mathrm{k} 39$ & 221 & 1,52 & $\mathrm{n} 64$ & 125 & 0,62 \\
\hline $\mathrm{k} 44$ & 168 & 1,24 & $\mathrm{n} 65$ & 93 & 0,53 \\
\hline $\mathrm{k} 45$ & 211 & 0,98 & $\mathrm{n} 66$ & 128 & 0,59 \\
\hline $\mathrm{k} 48$ & 262 & 0,99 & $\mathrm{n} 67$ & 115 & 0,59 \\
\hline $\mathrm{k} 49$ & 173 & 0,9 & $\mathrm{n} 70$ & 91 & 0,42 \\
\hline $\mathrm{k} 27$ & 454 & 3,16 & $\mathrm{n} 71$ & 51 & 0,24 \\
\hline $\mathrm{k} 29$ & 430 & 2,9 & $\mathrm{n} 63$ & 184 & 1,8 \\
\hline $\mathrm{k} 31$ & 508 & 3,07 & $\mathrm{n} 68$ & 278 & 1,49 \\
\hline $\mathrm{k} 35$ & 95 & 0,95 & $\mathrm{n} 69$ & 321 & 1,78 \\
\hline $\mathrm{k} 38$ & 371 & 2,49 & $\mathrm{n} 72$ & 88 & 0,88 \\
\hline $\mathrm{k} 42$ & 316 & 2,86 & $\mathrm{n} 73$ & 107 & 0,85 \\
\hline \hline Średnia & $\mathbf{2 6 8}$ & $\mathbf{1 , 7 3}$ & Średnia & $\mathbf{1 2 3}$ & $\mathbf{0 , 7 5}$ \\
\hline Odch. st. & $\mathbf{1 2 0 , 9 7}$ & $\mathbf{0 , 8 9}$ & $\mathbf{O d c h . ~ s t . ~}$ & $\mathbf{8 0 , 1 0}$ & $\mathbf{0 , 5 2}$ \\
\hline Wsp. zm. & $\mathbf{0 , 4 5}$ & $\mathbf{0 , 5 1}$ & Wsp. zm. & $\mathbf{0 , 6 5}$ & $\mathbf{0 , 6 9}$ \\
\hline \hline
\end{tabular}


Tabela 2

Liczba uszkodzeń analizowanych układów pojazdów [8]

\begin{tabular}{|c|c|c|}
\hline KOD UKLADU & Pojazdy typu I & Pojazdy typu II \\
\hline UK & 61 & 7 \\
\hline UH & 198 & 167 \\
\hline UZ & 50 & 29 \\
\hline UE & 1375 & 780 \\
\hline UW & 690 & 500 \\
\hline UN & 63 & 16 \\
\hline UJ & 103 & 80 \\
\hline US & 268 & 47 \\
\hline UO & 212 & 12 \\
\hline UC & 434 & 109 \\
\hline UP & 562 & 91 \\
\hline SUMA & $\mathbf{4 0 1 6}$ & $\mathbf{1 8 4 8}$ \\
\hline
\end{tabular}

W celu oceny wpływu uszkodzeń pojazdów na efektywność realizowanych przewozów stworzono ich klasyfikację na istotne i nieistotne z punktu widzenia ich wpływu na możliwość wykonywania zadania przewozowego. Uszkodzenia istotne to takie, których konsekwencją jest zjazd awaryjny uszkodzonego autobusu oraz konieczność wprowadzenia pojazdu rezerwowego. Uszkodzenia nieistotne to takie, które są możliwe do usunięcia przez jednostki pogotowia technicznego w przerwach pomiędzy wyznaczonymi kursami, bądź podczas obsługi codziennej. Liczby uszkodzeń istotnych i nieistotnych badanych pojazdów z punktu widzenia ich wpływu na możliwość realizacji zadania przewozowego przedstawiono w tabeli 3 .

Tabela 3

Liczba uszkodzeń istotnych i nieistotnych z punktu widzenia ich wpływu na możliwość realizacji zadania przewozowego [8]

\begin{tabular}{|c|c|c|c|c|c|}
\hline \multicolumn{3}{|c|}{ Pojazdy typu I } & \multicolumn{3}{c|}{ Pojazdy typu II } \\
\hline i & Istotne & Nieistotne & i & Istotne & Nieistotne \\
\hline \hline $\mathrm{k} 23$ & 54 & 131 & $\mathrm{n} 59$ & 12 & 26 \\
\hline $\mathrm{k} 33$ & 48 & 184 & $\mathrm{n} 60$ & 20 & 73 \\
\hline $\mathrm{k} 34$ & 32 & 152 & $\mathrm{n} 61$ & 12 & 53 \\
\hline $\mathrm{k} 37$ & 34 & 172 & $\mathrm{n} 62$ & 14 & 57 \\
\hline $\mathrm{k} 39$ & 52 & 169 & $\mathrm{n} 64$ & 25 & 100 \\
\hline \hline
\end{tabular}


cd. tab. 3

\begin{tabular}{|c|c|c|c|c|c|}
\hline \multicolumn{3}{|c|}{ Pojazdy typu I } & \multicolumn{3}{c|}{ Pojazdy typu II } \\
\hline i & Istotne & Nieistotne & i & Istotne & Nieistotne \\
\hline k44 & 40 & 128 & $\mathrm{n} 65$ & 17 & 76 \\
\hline $\mathrm{k} 45$ & 37 & 174 & $\mathrm{n} 66$ & 17 & 111 \\
\hline $\mathrm{k} 48$ & 47 & 215 & $\mathrm{n} 67$ & 19 & 96 \\
\hline $\mathrm{k} 49$ & 23 & 150 & $\mathrm{n} 70$ & 20 & 71 \\
\hline $\mathrm{k} 27$ & 98 & 356 & $\mathrm{n} 71$ & 9 & 42 \\
\hline $\mathrm{k} 29$ & 70 & 360 & $\mathrm{n} 63$ & 18 & 166 \\
\hline $\mathrm{k} 31$ & 66 & 442 & $\mathrm{n} 68$ & 29 & 249 \\
\hline $\mathrm{k} 35$ & 10 & 85 & $\mathrm{n} 69$ & 24 & 297 \\
\hline k38 & 62 & 309 & n72 & 18 & 70 \\
\hline k42 & 77 & 239 & n73 & 17 & 90 \\
\hline \hline Średnia & $\mathbf{5 0}$ & $\mathbf{2 1 7 , 7 3}$ & Średnia & $\mathbf{1 8}$ & $\mathbf{1 0 5 , 1 3}$ \\
\hline Odch. st. & $\mathbf{2 2 , 4 3}$ & $\mathbf{1 0 2 , 8 4}$ & Odch. st. & $\mathbf{5 , 2 6}$ & $\mathbf{7 6 , 1 4}$ \\
\hline Wsp. zm. & $\mathbf{0 , 4 5}$ & $\mathbf{0 , 4 7}$ & Wsp. zm. & $\mathbf{0 , 2 9}$ & $\mathbf{0 , 7 2}$ \\
\hline
\end{tabular}

\section{Podsumowanie}

Wspomaganie decydenta, w procesie podejmowania decyzji dotyczących realizacji procesu eksploatacji środków transportu, może być przeprowadzane poprzez prognozowanie zachowania się systemu eksploatacji oraz ocenę wpływu wybranych wariantów decyzyjnych na przebieg procesu eksploatacji. Pomocna w tym zakresie może być analiza wyników badań odnoszących się do uszkodzeń środków transportu.

W ogólnej liczbie uszkodzeń wszystkich badanych pojazdów, uszkodzenia usuwane przez jednostki pogotowia technicznego oraz w ramach obsługi codziennej stanowią około $70 \%$. Znaczna część uszkodzeń pojazdów są to uszkodzenie nieistotne z punktu widzenia ciągłości realizacji zadań przewozowych. Często są to uszkodzenia, których zarówno koszt, jak i czas naprawy są niewielkie. Wydaje się, że znaczna liczba zarejestrowanych tego typu uszkodzeń związana jest ze stosowanym w analizowanym systemie eksploatacji sposobem ewidencji uszkodzeń oraz metodami analizy czasu pracy pracowników podsystemu zapewniania zdatności [8].

W autobusach typu I zaobserwowano zwiększenie liczby uszkodzeń układu pneumatycznego w miesiącach zimowych w porównaniu z pozostałymi miesiącami roku. Wydaje się celowym zmodyfikowanie w okresie zimowym procedury realizacji obsługi codziennej w odniesieniu do pojazdów tego typu, a także wprowadzenie procesów diagnozowania stanu układu pneumatycznego jako obsługi profilaktycznej. 
Należałoby rozważyć możliwość ograniczenia obciążenia autobusów typu I realizacją zadań przewozowych oraz w miarę możliwości sukcesywnie wycofywać pojazdy tego typu $\mathrm{z}$ analizowanego systemu eksploatacji.

\section{Literatura}

1. Gałdzicki Z., Gołąbek A.: Niezawodność autobusów. Wydawnictwo Politechniki Wrocławskiej, Wrocław 1993.

2. Inżynieria niezawodności. Poradnik, pod red. J. Migdalskiego, ZETOM, Warszawa 1992.

3. Kostek R., Landowski B., Muślewski Ł.: Simulation of rolling bearing vibration in diagnostics. Journal of Vibroengineering, vol. 17, iss. 8, 2015.

4. Landowski B., Chabowski Ł.: Analiza wybranych charakterystyk uszkodzeń środków transportu. Studia i Materiały Polskiego Stowarzyszenia Zarządzania Wiedzą/Studies \& Proceedings Polish Association for Knowledge Management, $\mathrm{Nr}$ 46, 2011.

5. Landowski B., Muślewski Ł., Pająk M., Polishchuk O.: Method for initial assessment of unit costs of public city transport means operation. MATEC Web of Conferences 182, 01010, 17th International Conference Diagnostics of Machines and Vehicles, 2018, DOI: 10.1051/matecconf/201818201010.

6. Landowski B., Pająk M., Żółtowski B., Muślewski Ł.: Method of building a model of operational changes for the marine combustion engine describing the impact of the damages of this engine on the characteristics of its operation process. Polish Maritime Research, no 4 (96), vol. 24, 2017.

7. Landowski B., Perczyński D., Kolber P., Muślewski Ł.: An example of Markov model of technical objects maintenance process. Engineering Mechanics 2016, 22nd International Conference, Book of full texts: Institute of Thermomechanics Academy of Sciences of the Czech Republic, 2016.

8. Landowski B., Perczyński D.: Analiza uszkodzeń autobusów komunikacji miejskiej. $12^{\text {th }}$ International Conference on Developments in Machinery Design and Control, Nowogród 2008, CD.

9. Landowski B., Woropay M., Neubauer A.: Sterowanie niezawodnością w systemach transportu. Wydawnictwo ITE, Radom 2004.

10. Landowski B.: Numerical simulation of the process of a technical object state changes. Journal of KONBiN, vol. 45, 2018, DOI 10.2478/jok-2018-0013.

11. Muślewski Ł., Bojar P., Woropay M.: Identification and assessment of transport systems operations quality. Archives of Transport, 23 (3), 2011.

12. Muślewski Ł., Knopik L., Landowski B., Polishchuk O.: Analysis of assessment criteria for selected systems of transport means operation. MATEC Web of Conferences 182, 02003, 17th International Conference Diagnostics of Machines and Vehicles, 2018, DOI: 10.1051/matecconf/201818202003. 
13. Muślewski Ł., Landowski B., Mackiewicz N., Pająk M.: Research and analysis of work ergonomics of selected transport means operators. International Automotive Conference (KONMOT 2018), Materials Science and Engineering, 1757-8981, 2018, DOI:10.1088/1757-899X/421/3/032020.

14. Pająk M., Muślewski Ł., Landowski B.: Optimisation of changes of the operation quality of the transportation system in the fuzzy quality states space. International Automotive Conference (KONMOT 2018), Materials Science and Engineering; 1757-8981, 2018, DOI:10.1088/1757-899X/421/3/032023.

15. Transport, pod red. W. Rydzkowski, K. Wojewódzka-Król, PWN, Warszawa 1998.

16. Woropay M., Knopik L., Landowski B.: Modelowanie procesów eksploatacji w systemie transportowym. Wydawnictwo ITE, Bydgoszcz - Radom 2001. 